\title{
Impact core Competencies on Organizational Performance Study of its Application in Asia- Cell Communications Company in Babylon and Diwaniyah
}

\author{
Afrah Rahim Eidan \\ Middle Euphrates Technical University / Diwaniyah Technical Institute \\ afrah_2005@yahoo.com
}

\begin{tabular}{l}
\hline ARTICLE INFO \\
\hline Submission date: $11 / 10 / 2018$ \\
Acceptance date: $14 / 11 / 201$ \\
Publication date: $10 / 3 / 2019$
\end{tabular}

\begin{abstract}
This research discuss the fundamental capabilities and the importance of their impact on business organizations and organizational performance. The study of this topic is considered a vital issue in the Iraqi private sector in general and Asia Telecom for communications in particular. Where the researcher designed a questionnaire form consisting of (27) paragraphs for each axis of the research, where the research was applied to a random sample of (25) people of the administrators and accountants in Asia-Cell Telecom in Babylon and Diwaniyah was the problem of the study is increasing competition in the years The results were analyzed using statistical spss using a number of statistical indicators namely, arithmetic mean, standard deviation and relative importance. The regression analysis and the $\mathrm{t}(\mathrm{t})$ test were used for The researcher presented a recommendation to the company concerned about the need to pay attention to its resources, especially its human resources with expertise, skills and core competencies as a tool. A strategy to support their organizational performance and develop their knowledge and skills so that they can engage in a competitive war.
\end{abstract}

Key words: core competencies, organizational performance

$$
\begin{aligned}
& \text { تأثير المقدرات الجوهرية علذ الإداء التنظيمهي } \\
& \text { دراسة تطبيقه فخٍ شركة اسيا سيل للإتصالات في بابل والديوانية } \\
& \text { افراح رحيم عيدان } \\
& \text { جامعة الفرات الاوسط التثنية-الدعرد التتني الديوانية } \\
& \text { afrah_2005@yahoo.com }
\end{aligned}
$$

يسلط هذا البحث الضوء على المقدرات الجوهرية وبيان مدى اهميتها وتأثيرها على منظمات الاعمال والاداء التنظيمي ,إذ

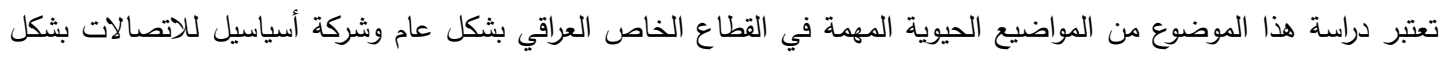

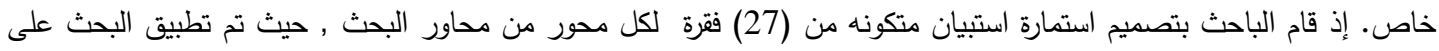

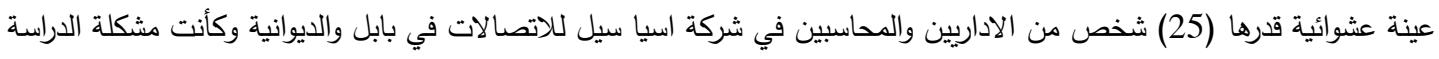

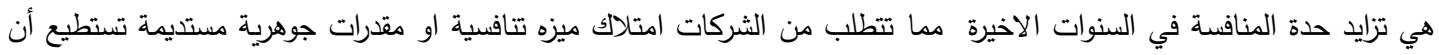

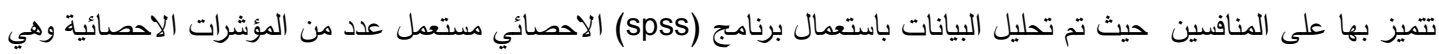

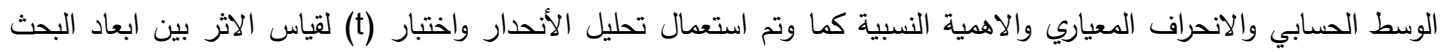


حيث تم التوصل الى وجود علاقة تأثير قويه بين ابعاد محاور البحث (الموارد التنظيمية ,مشاركة الرؤيا ,التمكين والتعاون) على ابعاد

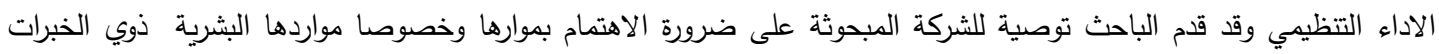

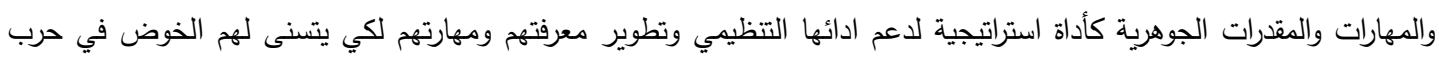

\section{المقدمة}

لا تزال الأزمة المالية العالمية الأخيرة تلقي ظلالها الداكنة على الأعمال التجارية العالمية، في حين أن

أسبابها ونتائجها لا تزال قيد الدراسة في معظم كليات الأعمال ومراكز الأبحاث في جميع أنحاء العالم. تعمل الاعل منظمات الأعمال بسرعة عالية لاستقرار أوضاعها المالية ومواقعها في مثل هذه الأسواق الصعبة، وإعادة بناء

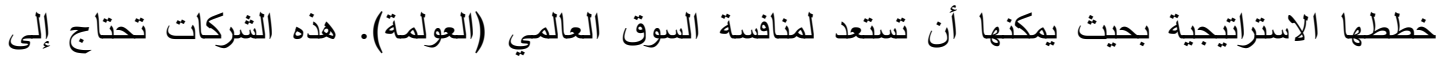
الاعتماد او التركيز على نقاط قوتهم الداخلية المتميزة لتوفير المزيد من القيمة المضافة للعملاء، والتمايز القوي

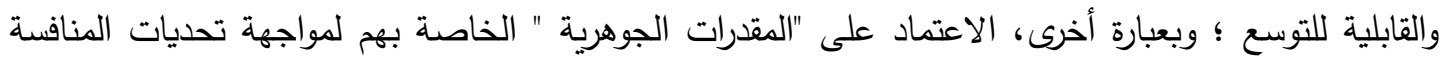

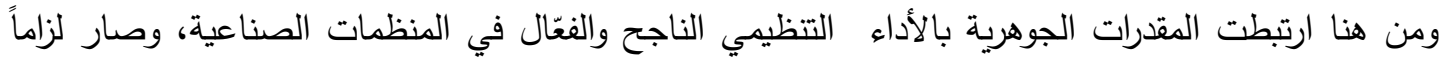
على المنظمة تسخير أفضل وأقصى ما عندها من قُرات جوهرية في سبيل الوصول إلى حالة من الاستقرار أولاً، ومن ثم التتافس والتغلب على الآخرين باستثمار ما متاح لديها من قدرات وما يمكن أن توفره لذللك، وتبرز

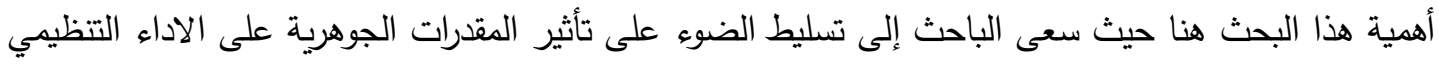

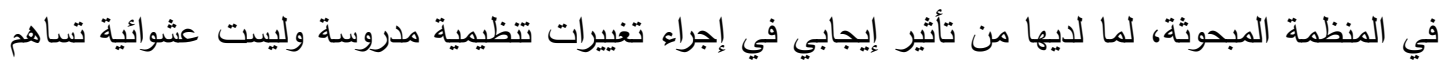
وبشكل كبير في إعطاء المنظمة ميزة تتافسية مستدامة. لقد قام الباحث بمراجعة الادبيات السابقة الخاصة بالعنوان المقدرات الجوهرية واثرها على الاداء التنظيمي وقسم البحث الى عدة مباحث حيث أن المبحث الاول يشمل منهجية البحث والمبحث الثاني تتاول الجانب النظري

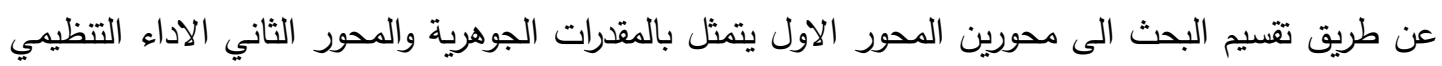
اما المبحث الثالث تتاول الجانب العملي للبحث اما المبحث الرابع تناول اهم الاستتاجات والتوصيات والمقترحات.

\section{1- 1 مشكلة الاراسة}

أدت التغيرات المتسارعة المحلية والدولية في بيئة الاعمال الى زيادة حجم التتافس بين مختلف المنظمات العاملة مما ساهم بقيام هذه المنظمات بتعزيز مكانتها التتافسية عن طريق سعيها لامتلاك مقدرة جوهرية تميزها

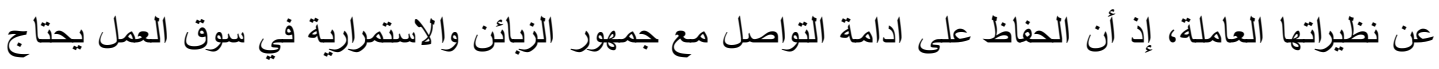
الى مواكبة التطورات الحاصلة في البيئة المحيطة ولا سيما الجانب التكنولوجي ومصادر توريد المواد الاولية بكلف منخفضة وامتلاك ملاكات فنية ذات كفاءة عالية، وفي ضوه ما ما تقدم يمكن صياغة مشكلة البحث

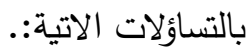

$$
1 \text { - ما مدى في توفر المقدرات الجوهرية لعينة الدراسة ؟ }
$$

2- هل هنالك تأثير للمقدرات الجوهرية على الاداء التتظيمي في الشركة ؟ 


\section{2 \\ تكمن اهمية البحث بالاتي :}

1 - أن موضوع المقدرات الجوهرية والاداء التتظيمي ذو اهية بالغة مما جعل الافراد العاملين في الثركة المبحوثة يكرسون جهدهم وادراكهم الشعوري اتجاه تحقيق الاهداف.

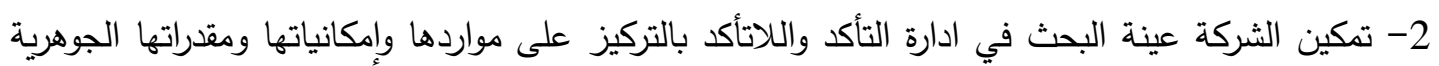
لمواجهة تحدي المنافسة الثديدة.

3- التصدي لمشكلة تواجها أغلب الشركات التي تتمثل بالتعقيد المرتفع للبيئة وسرعة التغيير والذي سينعكس على اداء المنظمة بشكل عام ولهذا نتائج هذه الدراسة يمكن الاستفادة منها في قطاعات ومنظمات اعمال مختلفة.

4-يحتل موضوع الاداء التتظيمي والمقدرة الجوهرية مكانة اساسية في المنظمة مما دعت الحاجة لدراسته بشكل مفصل

\section{3- اهد(ف الدراسة}

سعى البحث في جانبيه النظري والميداني إلى دراسة المتغيرين (المقدرات الجوهرية، الاداء التتظيمي) والعلاقة والأثر بينهما لتحقيق الأهداف الآتية: 1-التعرف على واقع المقدرات الجوهرية عن طريق تشخيص وتحليل أبعادها وأهميتها في المنظمة المبحوثة 2-الإطّلاع على واقع تبني المنظمة المبحوثة الاداء التظظيمي واستجابتها له.

$$
\text { 3- التعرف على العلاقة بين متغيري البحث . }
$$

4- التوصل إلى نتائج وتقديم مقترحات وتوصيات للشركة المبحوثة للاستفادة من المقدرات الجوهرية فيها

\section{المخطط الفرضي للارراسة}

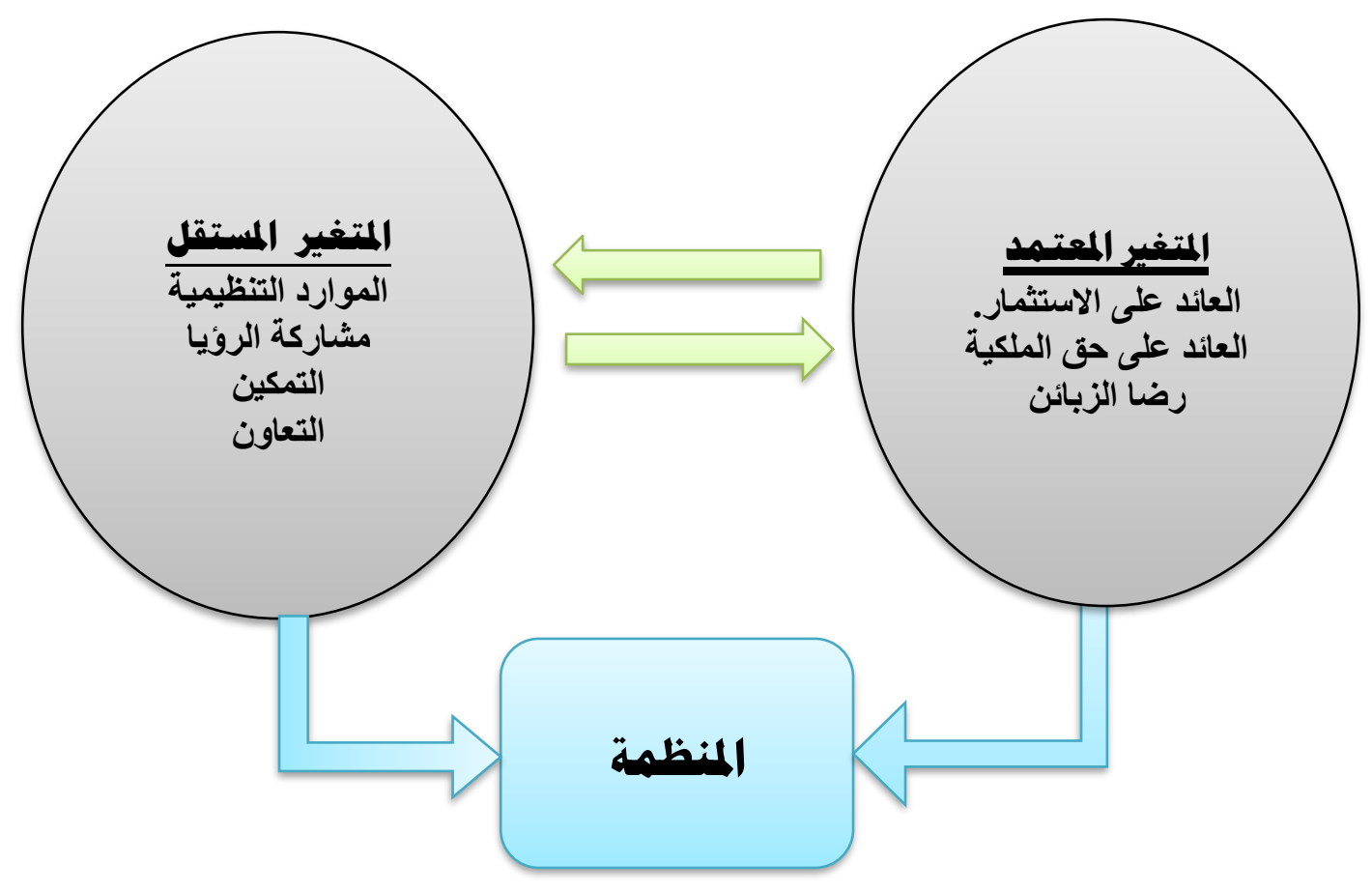




\section{5- 5 - 5رضيات الدراسة}

بناءّ على ما جاء في المخطط الفرضي اعلاه يمكن اشتقاق مجموعة من الفرضيات ينطلق منها البحث, قد يتم

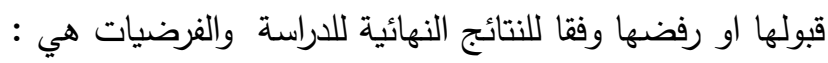

1. توجد علاقة تأثير ذات دلاله معنوية احصائية بين الموارد التتظيمية والعائد على الاستثمار

2. توجد علاقة تأثير ذات دلاله معنوية احصائية بين مشاركة الرؤيا والعائد على حق دلى الملكية

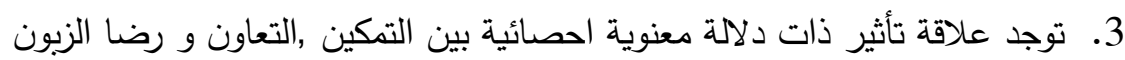

6- متغيرات البحث واساليب القياس

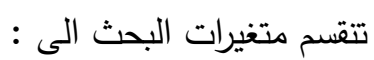

1 - المقدرات الجوهرية:- سوف يعتمد الباحث على القياس الذي وضعة كل من والذي تتبعه العديد من

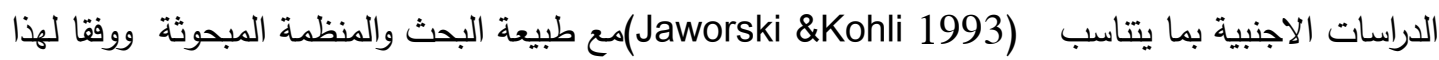
قسم الباحث المقدرات الجوهرية الى (الموارد ,مشاركة الرؤيا ,التمكين ,التعاون)ومن ثم ستعمل استمارة الاستبيان كأداة لجمع البيانات في قياس هذه المنظمة وتم وضع ستماره استبيان منظمة تحتوي على (27) فقرة وفق

مقياس

(ليكرت) الخماسي (اتقق تماما - لا اتفق تماما)

2- الاداء التنظيمي:- سوف يعتمد الباحث على القياس الذي وضعة كل من (Richs JES 2006)

العديد من الدراسات الاجنبية بما يتتاسب الذي تتبعه مع طبيعة البحث والمنظمة المبحوثة ووفقا لهذا قسم

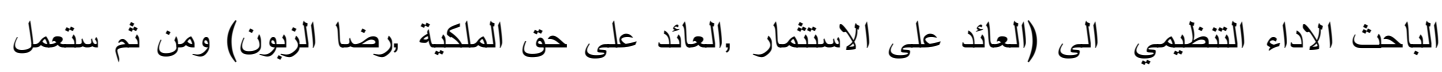

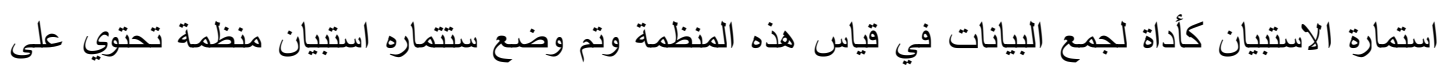
(27) فقرة وفق تدرج (ليكرت) الخماسي (اتفق تماما -لا اتفق تمام)

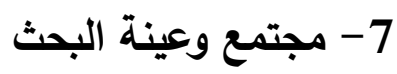

يتمثل مجتمع البحث في شركة اسيا سيل للاتصالات فرع بابل والديوانية وقد تم اختيار عينة من الموظفين في هذه الثركة من المحاسبين والاداريين بواقع (25) شخص عينه البحث وتم توزيع استمارة استبيان عليهم وتم تحليل التكرارات ادناه 
Journal of University of Babylon, Pure and Applied Sciences, Vol.(27), No.(1): 2019

\begin{tabular}{|c|c|c|}
\hline النسبة & التكرارات & العمر \\
\hline $32 \%$ & 8 & 20-30 سنه \\
\hline $48 \%$ & 12 & 31-40 سنه \\
\hline \multirow[t]{2}{*}{$2 \%$} & 5 & 41 فاكثر \\
\hline & & الجنس \\
\hline $56 \%$ & 14 & ذكر \\
\hline \multirow[t]{2}{*}{$44 \%$} & 11 & أنثى \\
\hline & & التحصيل الدراسي \\
\hline $88 \%$ & 22 & بكالوريوس \\
\hline \multirow[t]{3}{*}{$12 \%$} & 3 & ماجستير \\
\hline & 0 & دكتوراه \\
\hline & & التخصص العلمي \\
\hline $36 \%$ & 9 & أدارة اعمال \\
\hline $4 \%$ & 10 & محاسبة \\
\hline $0.4 \%$ & 1 & اقتصاد \\
\hline \multirow[t]{2}{*}{$2 \%$} & 5 & اخرى \\
\hline & & سنوات الخبرة \\
\hline $32 \%$ & 8 & اقل من 10 سنه \\
\hline $52 \%$ & 13 & 11-20 سنه \\
\hline $16 \%$ & 4 & 21 فاكثر \\
\hline
\end{tabular}

يتضح عن طريق الجدول اعلاه أن نسبة 48\% من حجم العينة هم من عمر فئة 31-40 وهذا يدل

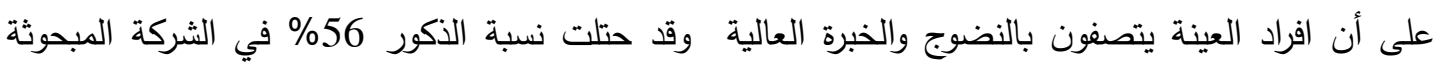

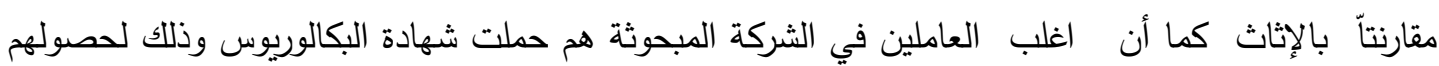

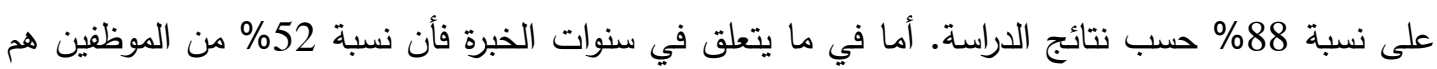
لايهه خبرة تتراوح بين 11-20 سنه. 


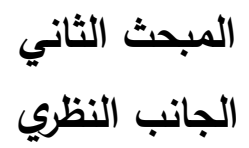

Core Competencies أولا: المقدرات الجوهرية مفهوم المقدرات الجوهرية لمفهوم المقدرات الجوهرية (Core Competencies) عدة معاني في كثير من المجالات اذ نجد في (لفي

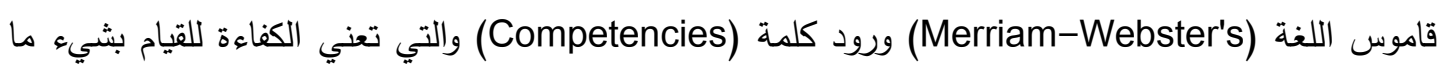

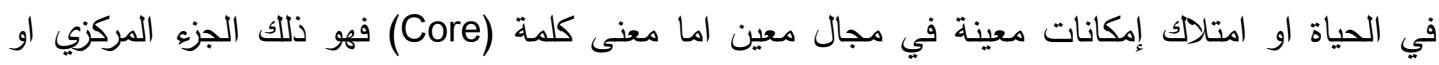

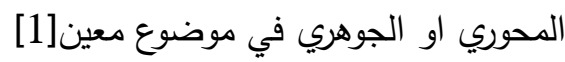
أما على مستوى الافراد (Individuals) فنجد أن (Christopher and Garson) يشيران على أنها

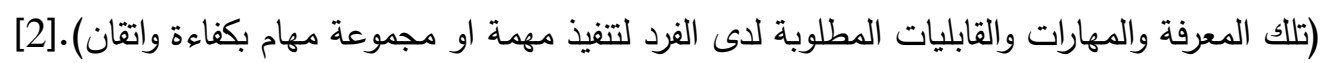
وعلى مستوى المنظمات فتعد المقدرات الجوهرية الطريق نحو الفرص المستقبلية للمنظمات التي تود الحصول

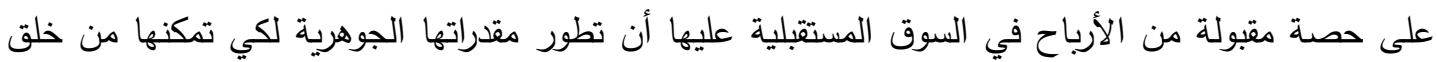
القيمة التي يرغب بها الزبون في المستقبل وبالتالي فأن هذا العمل يتطلب مدة زمنية قد تصل التئ فئل (10) سنوات

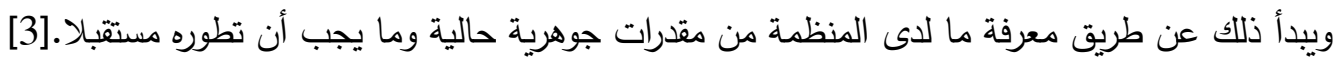
ويمكن تعريف المقدرات الجوهرية على أنها (تللك الموارد والمهارات الضرورية لبقائها ونموها) والمقدرات الجوهرية عرفت ايضا على أنها قدرات وخصائص المنظمة الفريدة في تطوير وتتسيق ودمج الموارد المتاحة لأنشاء مصدر للتمايز [ 4 ] عن طريق ما تقدم يمكن القول على أن المقدرات الجوهرية هي مهارات خاصة ,جودة ,خصائص معرفية

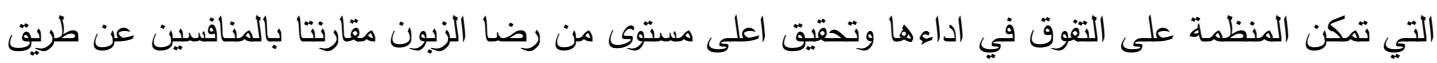
التكامل التكنلوجي للعمليات والموارد في نشاط واحد او كثر والتتسيق بين هذه الأنشطة. و وعلاوة على ما سبق يمكننا أن نستتتج أن المقدرات الجوهرية هي:1 - مزيج من الموارد والقابليات والأنشطة و العمليات و المعرفة داخل المنظمة المنئ. 2 - تعد حجر الزاوية في بناء الميزة التتافسية المستدامة. 3 - ما تجيده المنظمة بشكل أفضل من مثيلاتها. 4 - تسهم و الى حد كبير في اضافة قيمة للزبون.

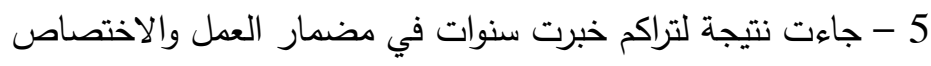

خصائص المقدات الجوهرية: Core Competences Characteristics يتقق اغلب الباحثين على أن اهم ما يميز المقدرات الجوهرية عن بقية المفاهيم المرادفة او المرتبطة بها هي

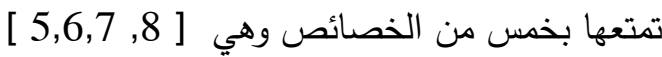

$$
\begin{aligned}
& \text { 1- الجمعية Collectiveness }
\end{aligned}
$$

بما أن المقدرات الجوهرية تمثل حالة من التآزر او التعاون بين بعض نشاطات الاعمال الخاصة بمنظمة ما،

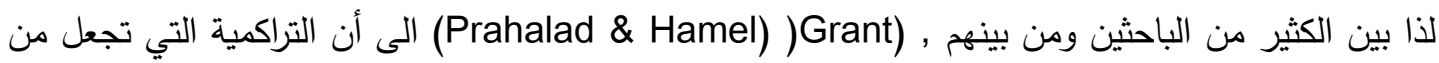
مقدرة المنظمة تتصف بالشمولية، تكون مفيدة في مجال الاعمال. وأن هذه المقدرات في ظروف عديدة تمكن المنظمة من الدخول الى قطاعات سوقية جديدة او تقديم منتجات جديدة. 


\section{Uniqueness التفرد 2}

لقد اكدت مداخل الادارة المعاصرة جميعا على أن التقرد يعد خصيصة بارزة للمقدرات الجوهرية، اذ يمكن أن يكون اداة او وسيلة لهنع المنافسين من تجريد المنظمة من الميزة التتافية الخاصة بها، والناجمة عن امتلاكها لمقدرة ما. ولتحقيق خاصية التفرد يجب توفر واحدة او اكثر من السمات الاتية:

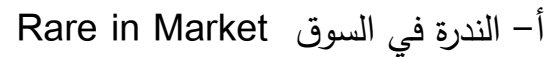

اذا توافر للمنظمة واحدة او اكثر من القدرات البارزة، تستطيع المنظمة أن تتمتع بميزة تنافسية عن طريق تتفيذها لاستراتيجية خلق القيمة المستندة الى هذه القدرات. فعلى سبيل المثال، قدرة شركة Sony في مجال صناعة الالكترونيات المصغرة تعد من القدرات النادرة في اسواق الالكترونيات العالمية. لذلك استطاعت الثركة لهنه

المذكورة أن تحمي الميزة التنافسية التي تتمتع بها في هذا المجال لمدة طويلة مقارنة بالثركات المنافسة لها. Inimitability بع صعبة التقليد وتثير الى المدى الذي لا يمكن تقليد موارد او قدرات منظمة ما من قبل المنافسين. فاذا كأن المورد او المقدرة تتميز بصعوبة التقليد، فأن هذا النوع من المقدرات سيحقق قيمة اضافية للمنظمة. ومن هذا المنطلق،

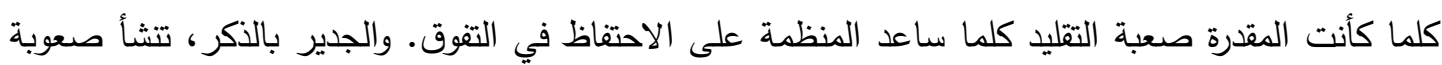
التقليد من عدم توافر المعلومات اللازمة بشكل كامل، فاذا كأنت المعلومات المتوافرة لدى المنافسين حول مقدرة معينة مشوشة او ناقصة، ففي مثل هذه الحالة تستطيع المقدرة أن تحمي خصوصيتها لمدة اطول. فعلى سبيل المثال، مقدرة (Wal-Mart) اللوجستية تجسدت في عملية معقدة عن طريق توافق عدد من الادوات (الاتصالات عبر الاقمار الاصطناعية، وأنظمة الطلب الاككتروني..الخ). وعلى الرغم من أن المنافس الرئيس

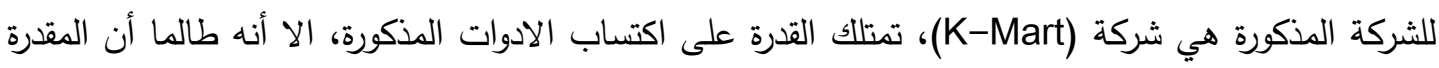

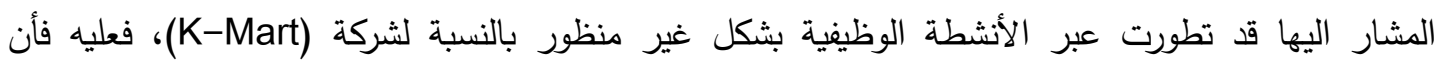

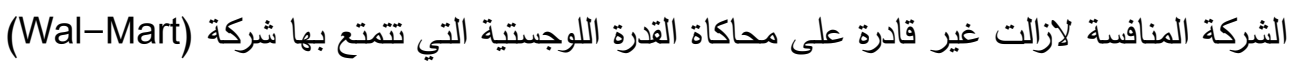

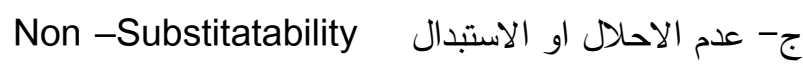

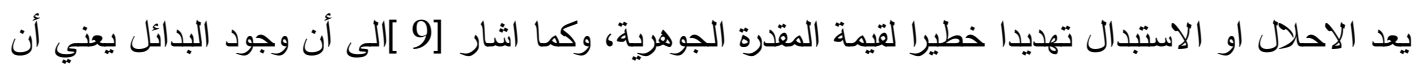

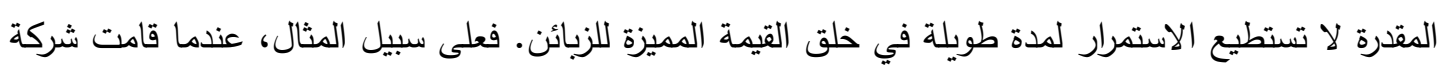

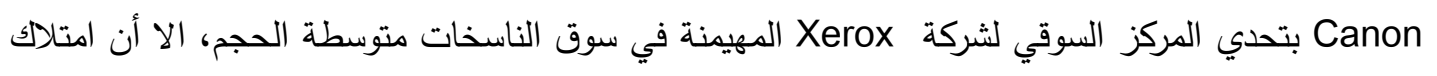
شركة Xerox لشبكة خدمات واسعة كأنت تثكل عائقا كبيرا امام شركة Canon. ولكن بعد أن استطاعت

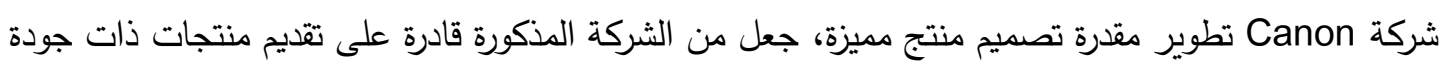

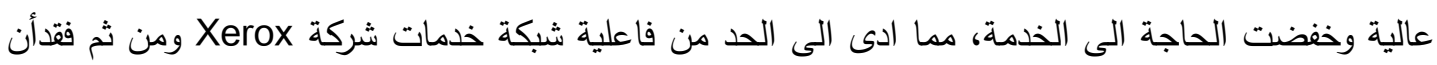
الشركة المذكورة لقدرتها في خلق القيمة للزبون.

3- الموارد والقدرات المكملة Complementray Resources \& Capabilities تشير الى ضرورة تتظيم المنظمة لنفسها بشكل يجعل منها قادرة على استغلال الموارد والقدرات المتاحة لها، وبما يضمن تحقيق افضل اداء مبتغى منها. ويتضمن عنصر التتظيم عدد من المكونات وهي هيكل اعداد

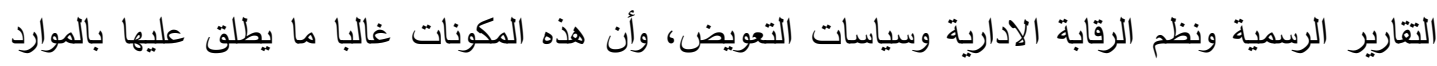

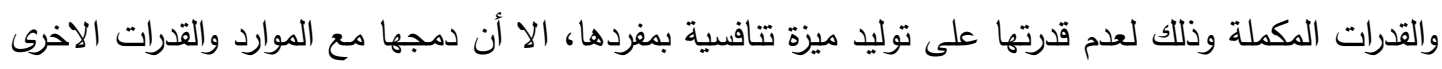
يمكن المنظمة من الوصول الى فهم افضل لسبل تحقيق الميزة التنافسية. 


\section{Superiority}

يفترض أن يضيف المورد قيمة للمنظمة عن طريق مساهمته في منح قيمة للزبون، وتشتق هذه القيمة من

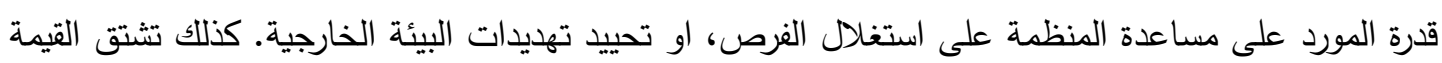
من قدرة المنظمة على تلبية رغبات الزبائن بطريقة او اسلوب يتقوق على قدرات المنافسين في هذا المجال.

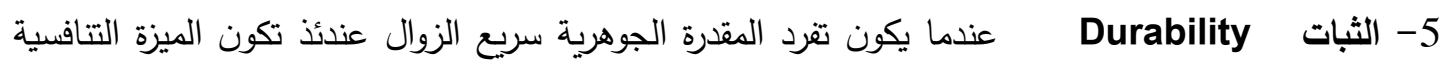
قصيرة الاجل وذات قيمة محدودة، والعكس هو الصحيح. وأن مدة بقاء تفرد المقدرة غالبا ما يرتبط بدورة حياة لتردية

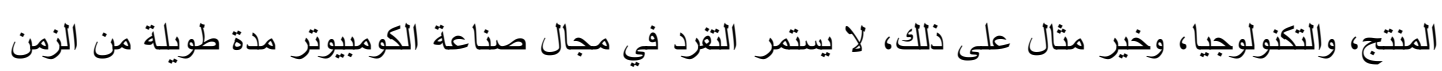
لقصر دورة حياة الكنتج والتكنولوجيا. أبعاد المقدرات الجوهرية دورة

\section{Resource organizational الموارد التنظيمية}

هي كل الموجودات، الإمكانيات البشرية، العمليات التنظيمية، ولمهارات والخصائص التنظيمية والمعلومات، والمعرفة. وقد تكون ملموسة كالمكائن، الأموال، المباني، أو غير ملموسة كسمعة المنظمة واسمها

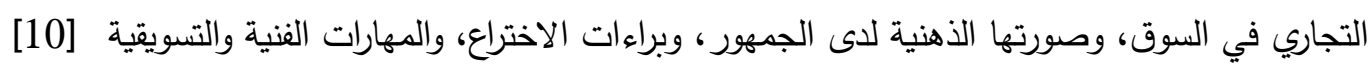

shared vision 20 2ؤية مشتركة

تُعرَّف الرؤية المشتركة على أنها مصلحة الشركة في مشاركة وجهة نظر المنظمة في الأهداف والغايات

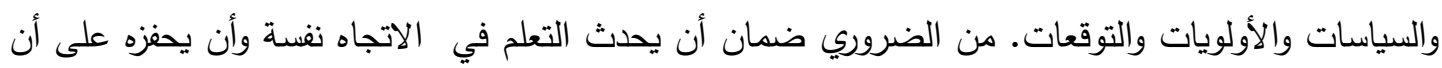

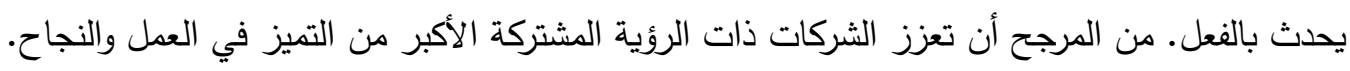

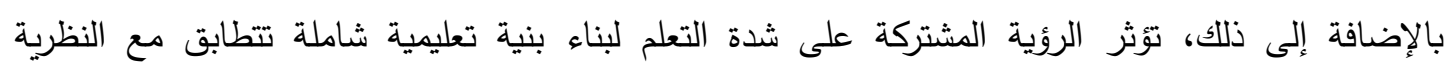

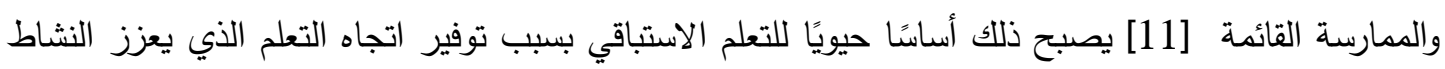
والالتزام والهدف بين أعضاء المؤسسة في البيئات الغامضة الذي يمثل الهدف الذي تستغله الثركة لإدارة

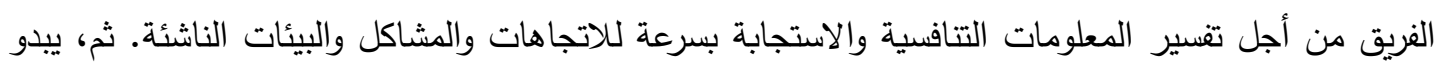

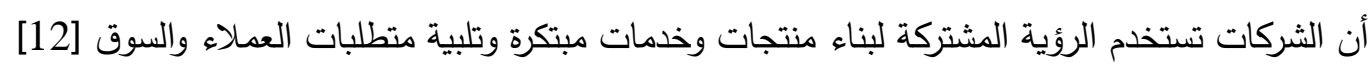
لتوسيع مفاهيم التعلم التظيمي إلى مخرجات التتظيمية، تلعب الرؤية المشتركة دوراً هاماً في توضيح كفاءة

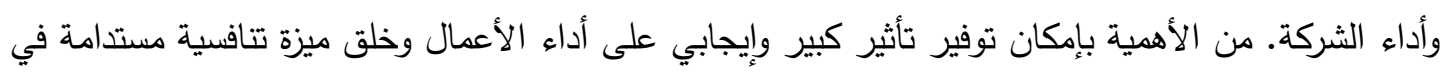
الشركة. تقوم الشركات بتتفيذها بشكل فعال لتوفير غرضها واتجاهها لتطوير كفاءتها وممارساتها وأدائها.

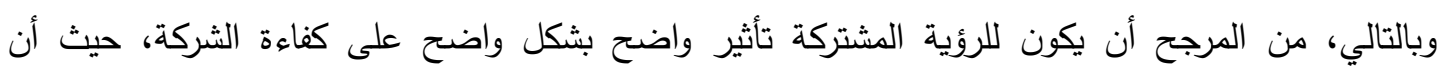

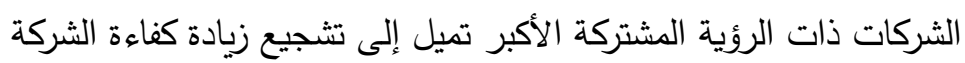

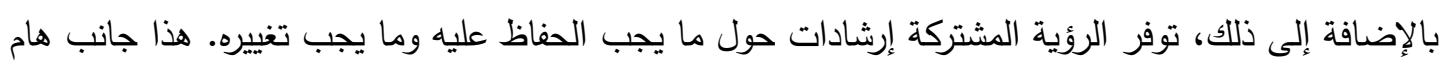

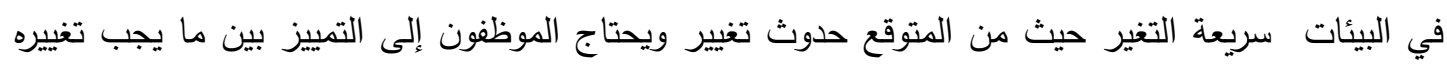

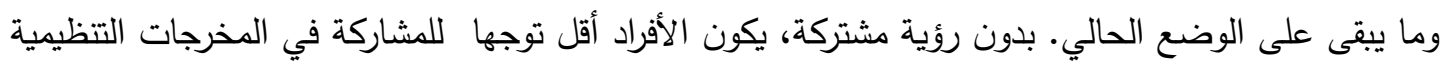

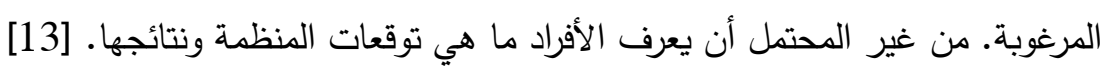


التعاون هو أيضا عامل رئيسي يلعب دورا في تطوير المقدرات الجوهرية. هو سلوك مشترك نحو هدف

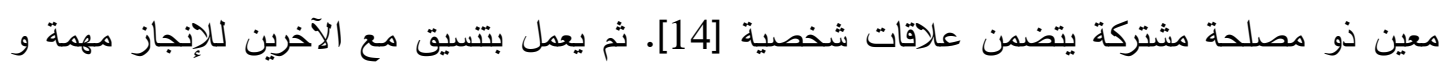
الاستجابة بشكل إيجابي للتعليمات والإجراءات ؛ العمل بشكل جيد مع أعضاء الفريق والأقران والمديرين. مشاركة المعلومات الهامة, العمل بفعالية عبر الوظائف ؛ تحديد مدى التعاون داخل مجاميع العمل او فرق لإئئ

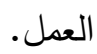

يعرف التعاون كمقدرة جوهرية متى وكيف يجتذب، ويعاد صياغة، ويستخدم فرق لتحسين النتائج. يعمل على بناء الثقة، وإلهام الحماس، وتشجيع الآخرين، ويساعد على حل الصراعات وتطوير التوافق في خلق افضل الأداء ممكن. [15]

\section{Empowerment التمكين}

أنها عملية أو حالة نفسية تتجلى في أربعة إدراك: المعنى، الكفاءة، العزم، والتأثير • على الاخرين ، يعني

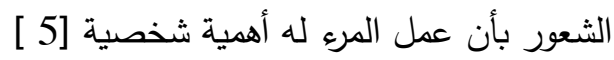

يتج التمكين إلى تعزيز جدوى العمل عن طريق مساعدة الموظف على فهم أهمية إسهامه في الفعالية

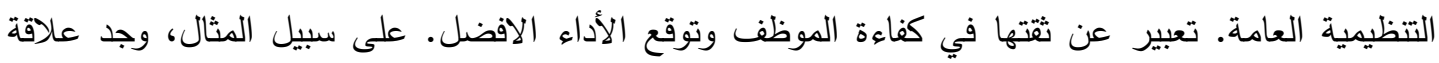

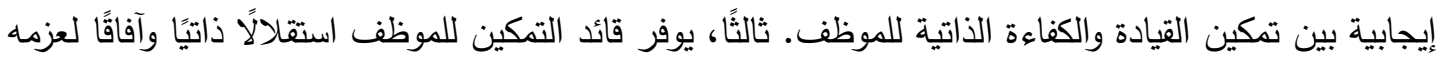
عن طريق تثجيع الفرد على تقرير كيفية تتفيذ وظيفته [16] وأخيرا، يعزز القائد التمكيني مشاركة الموظف في تئي

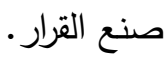

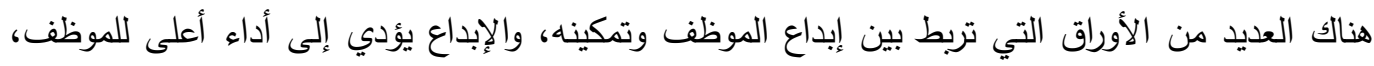
ومجموعة الموظفين والمنظمات. يشير الإبداع إلى أنتاج أفكار جديدة ومفيدة من قبل فرد الوراق أو مجموعة من الأفراد

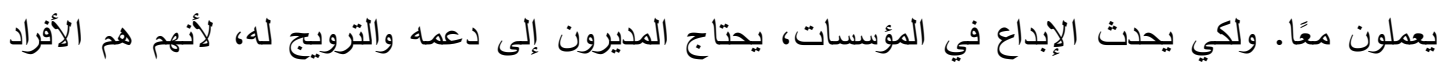

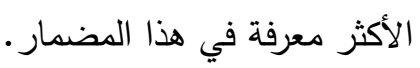

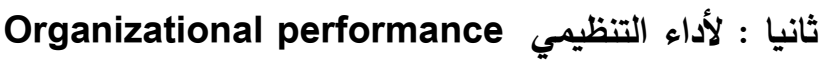

الأداء هو موضوع شائع في معظم فروع الإدارة، بما في ذلك الإدارة الاستراتيجية، وهو ذو أهمية للباحثين الأكاديميين والمديرين الممارسين. الأداء هو النتيجة النهائية للأنشطة، ويشمل النتائج الفعلية لعملية الإدارة الاستراتيجية. يبرر ممارسة الإدارة الاستراتيجية من حيث قدرتها على تحسين أداء المنظمة [17] ويشمل الإداء

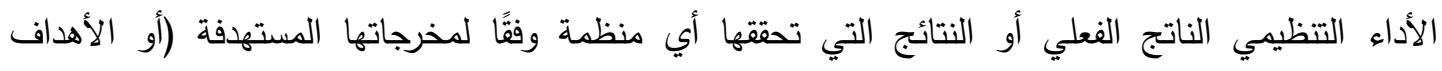
والغايات). وفقا[18] يشمل الأداء التظيمي ثلاثة مجالات محددة للنتائج الثابتة:

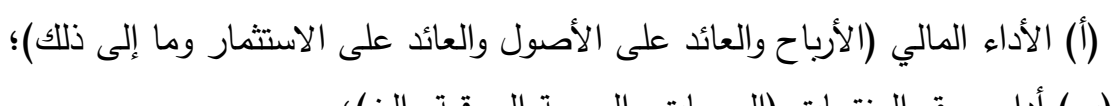

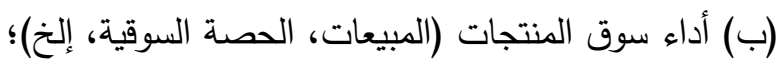
(ج) وعائدات المساهمين (إجمالي حقوق المساهمين، القيمة الاقتصادية المضافة، وما إلى ذلك). 
يختلف البحث في الأداء التظيمي كوظيفة لمختلف المخرجات. يمكن تصنيف مجموعة متتوعة من

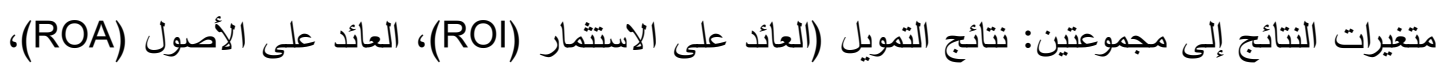

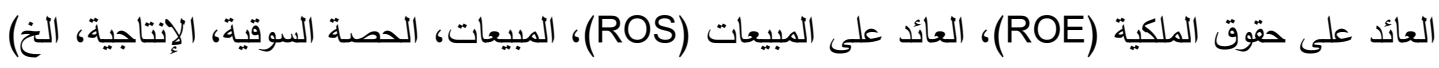

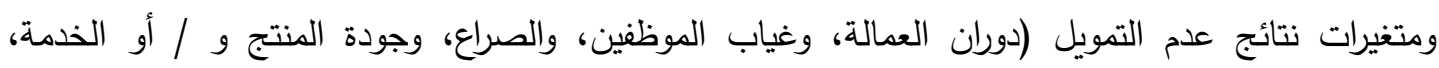

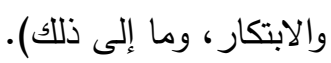

أن تعدد البيئات التتافسية التي تواجهها الشركات في صناعات مختلفة، تهدف الى معرفة الأرقام المالية المطلقة فقط مثل المبيعات، أو الأرباح، أو التدفق النقدي ليست ذات الهية مات ما لم يتم النظر إليها في سياق

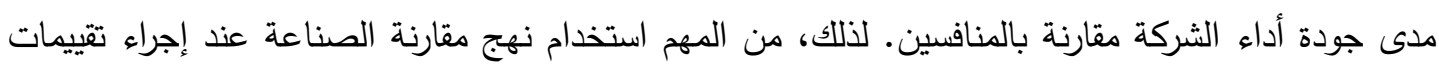

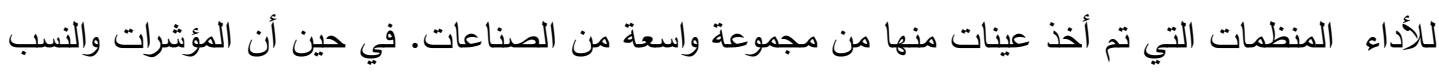

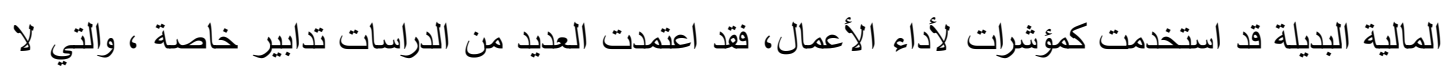
يمكن أن تستخدم إلا كدليل لديها. يعتبر أداء العمل متعدد الأبعاد بطبيعته وقد تكون الإجراءات المحاسبية مضللة بسبب

$$
\text { (1) التعامل غير الملائم مع الأصول غير الملموسة و }
$$

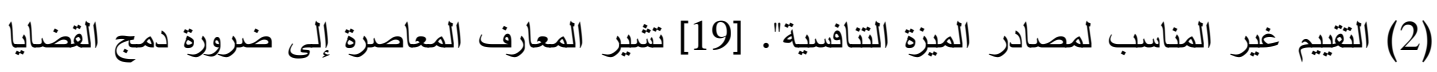
القائمة على المحاسبة مع الأصول القائمة على السوق من أجل توليد تقييم أكثر رسوخاً لخصائص أداء الأعمال. العديد من الأسباب وراء هذا الاهتمام متعدد الأبعاد في تقييم أداء الأعمال.

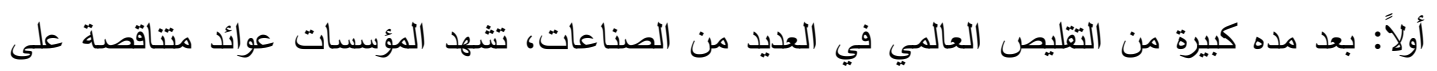

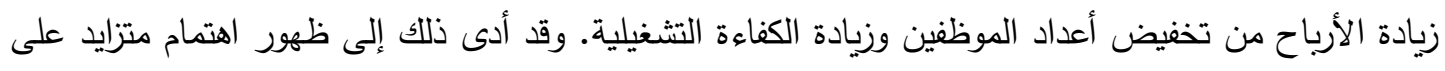
محركات النمو المستقبلية (المبيعات) مع اعتبار الأداء المرتكز على السوق أساسيًا لمثل هذا التطور ـ ثانيا،

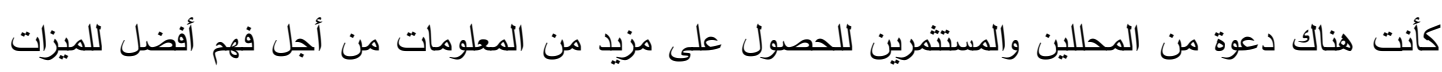

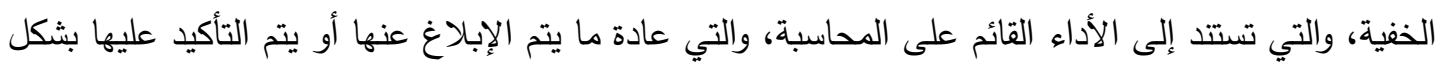
سيئ في التقارير السنوية والبيانات المالية. ثالثًا: تتطلب أساليب التحسين التتافسية المستمرة من قبل الثركات أن تقوم بدور العميل في القرار التتظيمي أبعاد قياس الاداء التنظيمي يتبين عن طريق مراجعة البحوث والكتابات المتعلقة بكيفية قياس الاداء التتظيمي ذات الصلة بهذا البحث

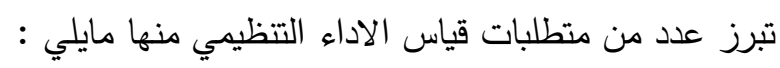
- يفضل عدم الاعتماد على المعايير المالية او الكمية فقط لا أهمية توفر المعايير التشغيلية والنوعية ايضا ليجري قياس الاداء المنظمي في جوانبه الكمية والنوعية. - عدم التوسع في عدد ابعاد قياس الاداء المنظمي (المالية التثغيلية) لتسهيل عملية القياس أن يغطي مقياس

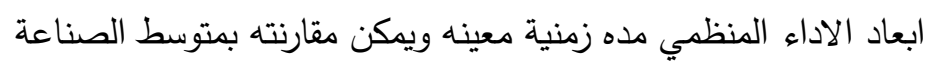

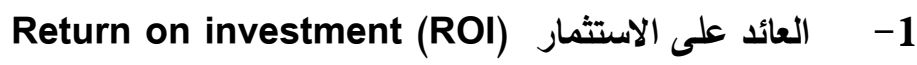

يعد العائد على الاستثمار (كالعائد على حق الملكية) من معايير قياس الاداء على مستوى المنظمة التي

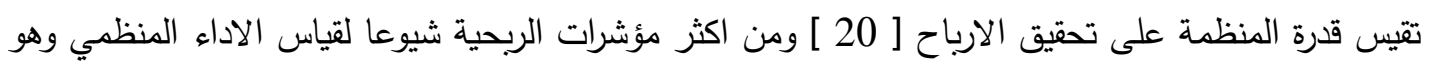


حاصل قسمة صافي الدخل بعد الضريبة على مجموع الموجودات. مأخذ هذا المؤشر ومنها اختلاف طرق

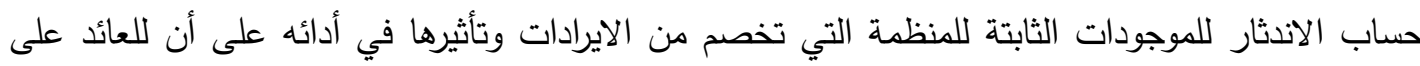
الاستثمار مزاياه المتعددة منها اعطاؤه صوره شاملة عن قدرة موجودات المنظمة على تحقيق الارباح واتخاذ

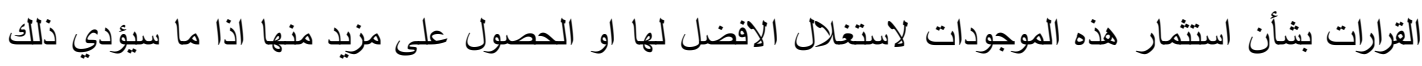
الى زيادة العائد منه.

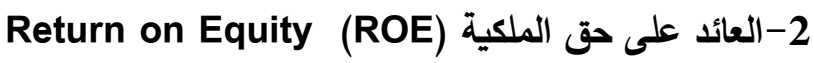

يحسب بقسمة الدخل الصافي بعد الضريبة على حقوق المساهين وحقوق الملكية هو راس المال والاحتياطات والارباح المحتجزة وتقيس هذه النسبة ربحية المنظمة فيما يتعلق بحقوق الملكية , اي العائد الذي لهي

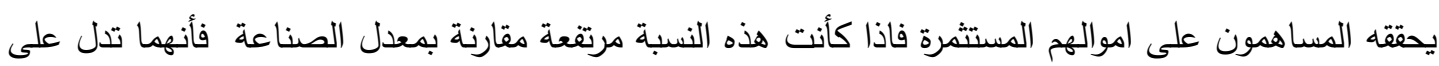
اداء اعلى لها . الحعهاء

\section{Costumers satisfaction 3- رضا الزبائن}

يعد رضا الزبائن من اهم المؤشرات لقياس اداء المنظمات الذي حظي بتأكيد الكتاب والباحثين في علوم

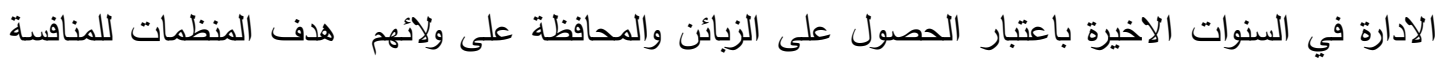

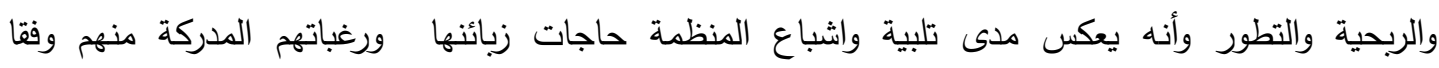
لتقضيلاتهم او اولوياتهم افضل من المنافسين كتلبية حاجات الزبائن بشكل تتافسي عن طريق تقديم خدمات تعليمية جامعية بأفضل خصائص ممكنه الطرق الرئيسية لتعزيز تتافسية المنظمة هو مواصلة تقديمها خدمات جديده ذات نوعية افضل مما يقدمه

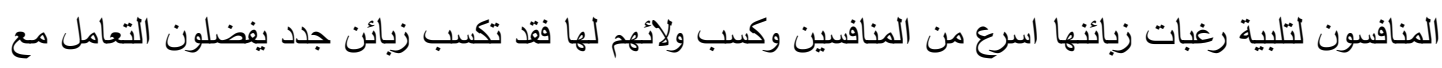

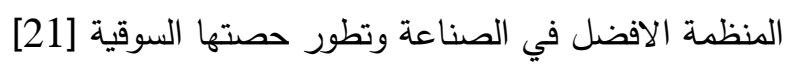
المبحث الثالث

(الجانب العملي (التطبيقي)

أولا/ تحليل نتائج الاستبانة لأغراض البحث فقد تم تفريخ وتحليل البيانات عن طريق برنامج(spss) للقيام بعملية التحليل، وتحقيق

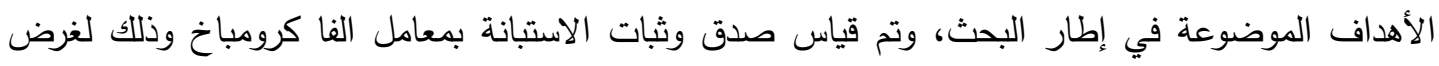

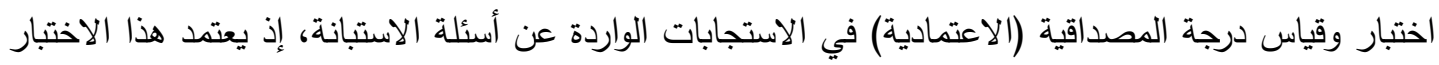
على مدى الثبات الداخلي ودرجة الاعتمادية لأسئلة الاستبانة.

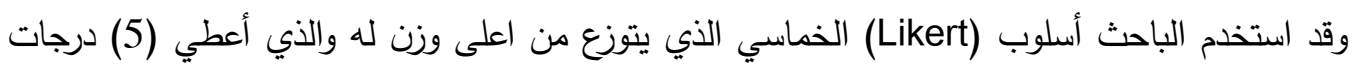

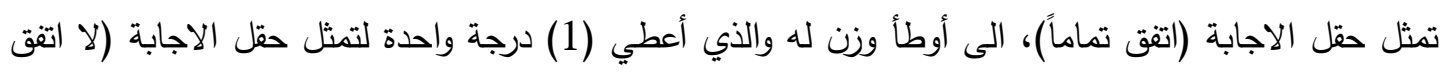

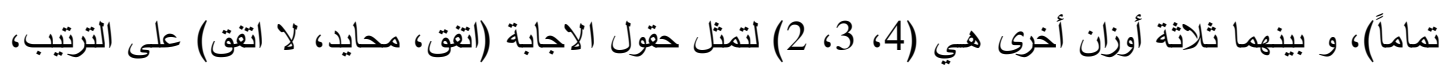

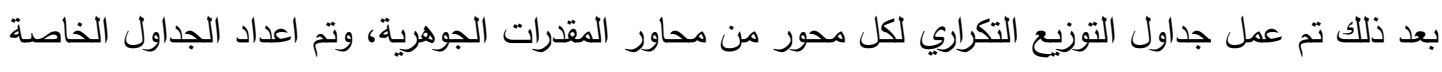

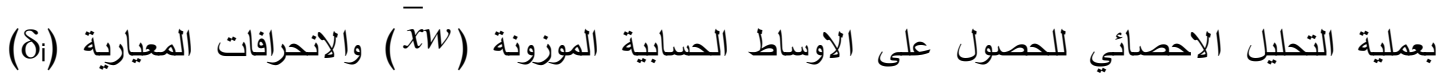


ومعاملات الاختلاف (C.V) والأوزان المئوية (\%)، بهدف التعرف على مدى الانسجام في استجابات العينة،

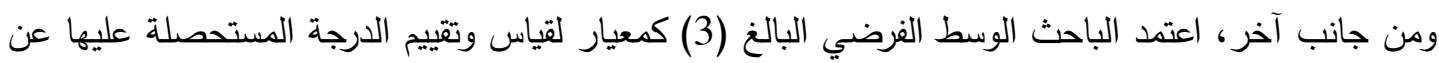

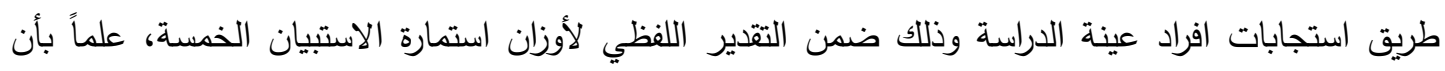
$3=\frac{1+2+3+4+5}{5}$

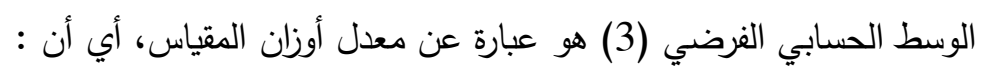

الجدول رقم (1) معامل ثبات المحوري الدراسة.

\begin{tabular}{|c|c|c|}
\hline \multicolumn{3}{|c|}{ معامل الثبات (طريقة ألفا كرو نباخ) } \\
\hline معامل ألفا كرو نباخ للثبات & عدد الفقرات & 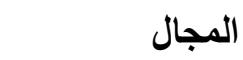 \\
\hline .989 & 17 & المقدرات الجوهري \\
\hline .960 & 10 & الاداء التنظيمي \\
\hline & & المصدر : إعداد الب \\
\hline
\end{tabular}

يتبين عن طريق جدول رقم (1) هومعامل الثبات الفا كرونباخ حيث حصلت فقرات المحور الاول المقدرات

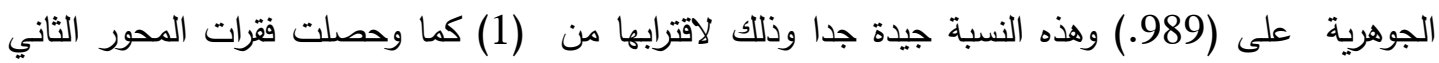
الاداء التظيمي على (960.) وهذه ايضا مؤشر جيد لاقترابها من 1 وهنه

أولا : اختبار متغيرات المقدرات الجوهرية الجدول رقم (2) الاوساط الحسابية والانحرافات المعيارية والاهمية النسبية للمتغير المقدرات الجوهري

\begin{tabular}{|c|c|c|c|c|}
\hline الاهمية & الأنحراف & الوسط & الفقرات & ت \\
\hline \multicolumn{5}{|c|}{ أولا الموارد التظظيمية } \\
\hline 0.795 & .978 & 4.04 & 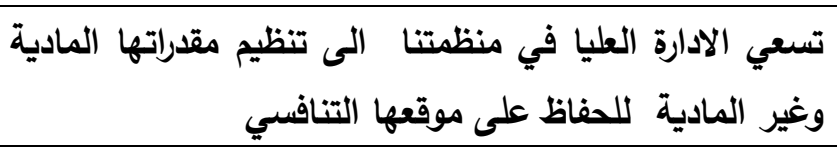 & 1 \\
\hline 0.795 & .995 & 4.36 & تصيغ منظمتا استراتيجية مبدعة لتنظيم مقدراتها المادية & 2 \\
\hline 0.815 & 1.038 & 3.92 & تمتلك منظمتنا مورد مادي وتنظيمي تمكنها من تقديم خدمه & 3 \\
\hline 0.865 & .712 & 4.56 & تضتلك منظمتنا تكنلوجيا معلومات متطورة تساعده على تقديم & 4 \\
\hline 0.817 & 0.930 & 4.22 & المتوسط العام & \\
\hline \multicolumn{5}{|c|}{ مشاركة الرؤيا } \\
\hline 0.865 & .764 & 4.40 & رؤية المنظمة واضحة لموظفيها & 5 \\
\hline 0.865 & .852 & 4.32 & استراتيجية لمنظمتنا شاملة ومرنه & 6 \\
\hline
\end{tabular}


Journal of University of Babylon, Pure and Applied Sciences, Vol.(27), No.(1): 2019

\begin{tabular}{|c|c|c|c|c|}
\hline 0.840 & 1.020 & 4.04 & أنا اشعر أن قيمتي الحقيقيه في المنظمة & 7 \\
\hline 0.586 & 0.878 & 4.25 & المتوسط العام & \\
\hline \multicolumn{5}{|c|}{ التمكين والتعاون } \\
\hline $77.00 \%$ & .954 & 4.08 & هيكل المنظمة صنية صناعة القرار يتم نقلها الى المستويات الادنى في & 8 \\
\hline $84.50 \%$ & .935 & 3.96 & الافراد لايهم القدرة على التوجيه والتغير في عملهم & 9 \\
\hline $89.60 \%$ & .770 & 4.48 & معرفة الافراد في عملهم يعتبر اساس نجاح المنظمة & 10 \\
\hline $78.45 \%$ & .988 & 4.32 & أتحمل مسؤولية ما أقوم به من أعمال ولدي الاستعداد & 11 \\
\hline $84.43 \%$ & 1.118 & 3.60 & كل الموظفين ملتزمين لنفس الهدف (هدف الشركة) & 12 \\
\hline $79.92 \%$ & .757 & 4.36 & اغلب المشاكل التي تظهر يتم معالجتها بشكل جماعي & 13 \\
\hline $85.25 \%$ & 1.440 & 3.64 & يستطيع الفرد تأسيس قواعد واجراءات لتطوير عملة & 14 \\
\hline $77.00 \%$ & .988 & 4.32 & هنالك جهود تعاونية بين الموظفين لتنفيذ مهام صعبة & 15 \\
\hline $84.43 \%$ & 1.000 & 4.40 & تحفز ادارة الثركة جميع الافراد العاملين على تقديم افكار & 16 \\
\hline $85.25 \%$ & .458 & 4.72 & نستثمر علاقاتنا مع الجميع من اجل الحصول على افكار & 17 \\
\hline $84.50 \%$ & 0.78 & 4.32 & ط العام & المتوا \\
\hline
\end{tabular}

*"المصدر : اعداد الباحث بالاستتاد على نتائج الحاسوب

ي

شير جدول رقم (2) الى الاوساط الحسابية والانحرافات المعيارية والاهمية النسبية التي تتعلق بإجابات العاملين

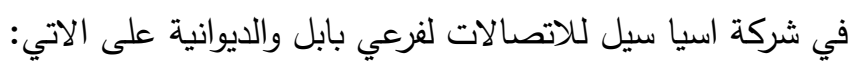
أ- الموارد التنظيمية:

بين الجدول رق (2) أن الموارد التنظيمية ذات مستوى مرتفع وهذا ما يؤكده الوسط الحسابي العام للمتغير والذي بلغ (4.22) وهو اعلى من الوسط الحسابي الفرضي والذي يبلغ (3) وبانحراف معياري عام

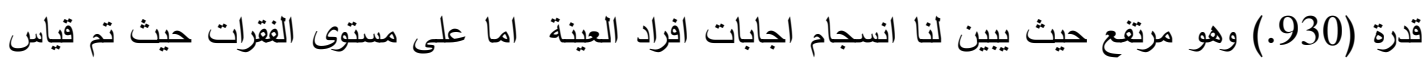

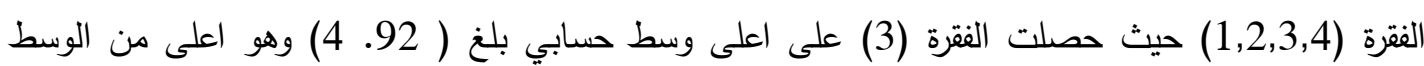
الحسابي الفرضي والبالغ (3) وبانحراف معياري قدرة (1.38) هذا يدل أن هنالك اهتمام من قبل الثركة في الموارد التظيمية والبشرية الموجودة وليع البردية

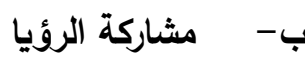

عن طريق الجدول رقم (2) أن المنظمة تستخدم هذا البعد بشكل جيد اي أنها تقوم بمشاركة رؤياها بين موظفيها وهذا واضح عن طريق الوسط الحسابي العام حيث بلغ (( 4.25 وهو اكبر من الوسط الحسابي الفرضي والذي يبلغ (3) وحصل نفس البعد على انحراف معياري قدرة (0.787) وهو اصغر من 1 الصحيح هذا يدل على قلة تشتت الاجابات. 
ج- التمكين والتعاون

عن طريق جدول رقم (2)أن الوسط الحسابي العام لهذا المتغير قد بلغ (4.32) وهو اكبر من الوسط الحسابي الفرضي والذي يبلغ (3) وهذا يدل على أن الشركة تدعم روح التعاون بين افراد موظفيها كما وتسمح لهم بالمشاركة في اتخاذ القرارات المتعلقة في العمل وحصل نفس البعد على انحراف معياري قدرة (458.) وهو اصغر من 1 هذا يعني أن تشتت الاجابة قليلة بين افراد العينة.

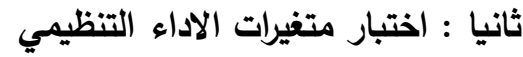

الجدول رقم (3) الاوساط الحسابية والانحرافات المعيارية والاهمية النسبية لمتغير الاداء التنظيمي ·

\begin{tabular}{|c|c|c|c|c|}
\hline الاهمية النسبية & 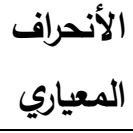 & الوسط الحسبي & الفقرات & ت \\
\hline \multicolumn{5}{|c|}{ العائد على الاستثمار } \\
\hline 0.9700 & 1.464 & 3.68 & نسبة العائد على الاستثمار ترتبط بمبادئنا التتافسية & 1 \\
\hline 0.865 & 1.200 & 4.24 & يزداد الرضا النفسي كلما زاد العائد الكلي & 2 \\
\hline 0.865 & 1.012 & 4.24 & الثعور بالقيمة النفسية عندما تزداد المبيعات & 3 \\
\hline 0.823 & .963 & 4.48 & فرصتم بتطوير الاعمال التي نتمكن عن طريقها من خلق واستثمار & 4 \\
\hline 0.8230 & 1.159 & 4.16 & الوسط الحسابي العام & \\
\hline \multicolumn{5}{|c|}{ العائد على حق الملكية } \\
\hline 0.790 & .748 & 4.68 & لاى المنظمة الموارد الكافية لتغطية النفقات التشغيلية & 5 \\
\hline 0.830 & .277 & 4.92 & تقوم المنظمة بمتابعة دورية على الكلف والمصروفات & 6 \\
\hline 0.920 & .638 & 4.64 & لدى المنظمة معرفة كافية بالأهداف المالية & 7 \\
\hline 0.8400 & 0.554 & 4.74 & الوسط الحسابي العام & \\
\hline \multicolumn{5}{|c|}{ رضا الزبون } \\
\hline $80.00 \%$ & 1.338 & 4.04 & رضا الزبون هدف مهم بالنسبة للمنظمة & 8 \\
\hline $91.2 \%$ & .712 & 4.56 & الزبون على حق دائما & 9 \\
\hline $82.00 \%$ & 1.464 & 3.68 & تسعي المنظمة أن تجعل الزبون عميل دائم & 10 \\
\hline $79.00 \%$ & 0.86 & 4.24 & \multicolumn{2}{|c|}{ المتوسط العام } \\
\hline
\end{tabular}

*/لمصدر: اعداد الباحث بالاستناد على نتائج الحاسوب 
يبين جدول رقم (3) الاوساط الحسابية والانحراف المعياري والامية النسبية لأبعاد محور الاداء التنظيمي وكما يلي : أ- أ العمائد على الاستثمار

بين جدول رقم (3) أن هذا المتغير حصل على وسط حسابي عام قدرة (4.16) وهو اكبر من الوسط الحسابي الفرضي والبالغ (3) هذا يدل على أن هذا المتغير محط اهتمام افراد العينة حيث تعتبر من اولى لهاتى اهتمامات الشركة لنسبة العائد حيث حصل نفس المتغير على أنحرف معياري قدرة (1.59) هنالك تشتت قليل في اجابات الموظفين كونه اعلى من 1 الصحيح ب- العائد على حق الملكية ت- يتضح عن طريق جدول رقم (3) أن هذا المتغير قد حصل على وسط حسابي عام (4.74) وهو اكبر من الوسط الحسابي الفرضي الذي يبلغ (3) هذا يدل على أن هناللك اهتمام من قبل الشركة المبحوثة

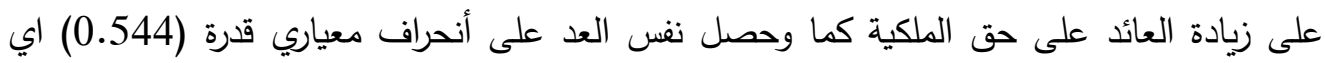
يعني أن تشتت اجابات الدراسة قليل جدا.

ثالثا/ تحليل علاقة الارتباط ونقصد بها التحقق من صحة فرضية الارتباط بين متغيرات المقدرات الجوهرية والاداء التنظيمي

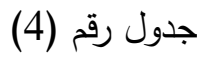
قيم معامل الارتباط ( person) بين متغيرات المقدرات الجوهرية والاداء التنظيمي

\begin{tabular}{|c|c|c|c|}
\hline sig المعنوية & الاداء التظظيمي & المتغيرات & $ت$ \\
\hline 0.05 & 0.981 & الموارد التظظيمية & 1 \\
\hline 0.05 & 0.745 & مشاركة الرؤيا & 2 \\
\hline 0.05 & 0.701 & التمكين & 3 \\
\hline 0.05 & 0.692 & التعاون & 4 \\
\hline
\end{tabular}

• • اعداد الباحث استنادا الى نتائج الحاسوب

$$
\text { عن طريق جدول (3) يبين ما يلي }
$$
1- توجد علاقة ارتباط طردية موجبة قوية عند معنوية (0.05) بين الموارد التظظيمية والاداء التظظيمي حيث بلغ معامل الارتباط (0.980) وهو توضيح لاستخدام الموارد المادية والتنظيمية في الشركة. 2- توجد علاقة ارتباط طردية قوية بين مشاركة الرؤيا والاداء التنظيمي عند مستوى معنوية (0.05) بين

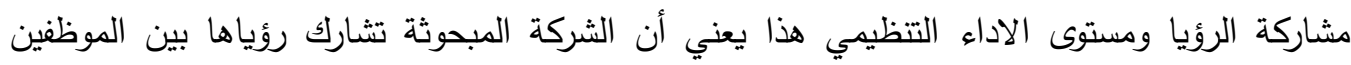
بشكل فعال حيث بلغت قيمة الارتباط (0.745) 3- توجد علاقة ارتباط قوية وموجبة بين كل من التمكين والتعاون والاداء التظظيمي عند مستوى معنوية

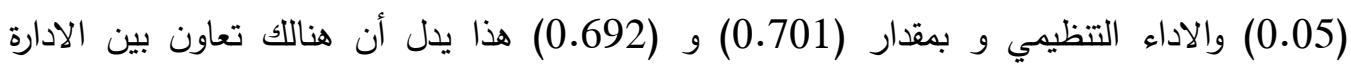
وموظفيه وكذبك هناللك فرصة للمشاركة في اتخاذ القرارات. 
رابعا: تحليل اثر العلاقة بين متغيرات المقدرات الجوهرية ومستوى الاداء التنظيمي الجدول (4) تحليل أثر العلاقة بين متغيرات المقدرات الجوهرية والاداء التظظيمي

\begin{tabular}{|c|c|c|c|c|c|}
\hline قيمة T & معدل الانحدار & قيمة F & $\mathbf{R}^{2}$ & المتغيرات & ت \\
\hline 0.287 & 0.038 & 0.069 & .980 & الموارد التتظيمية & 1 \\
\hline 1.654 & 0.203 & 2.056 & .854 & مشاركة الرؤيا & 2 \\
\hline 0.654 & 0.033 & 0.053 & .067 & التمكين & 3 \\
\hline 0.945 & 0.103 & 0.519 & .586 & التعاون & 4 \\
\hline
\end{tabular}

P-Value ** تساوي $6.60($ الجدولية عند مستوى معنوي 0.05 وبدرجة حرية

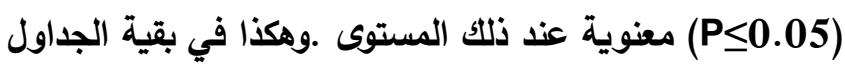
عن طريق جدول رقم (4) مايلي

يوضح معامل التحديد (R2) المعدل أن نسبة الاختلاف المفسر بلغت (0.980) للموارد التنظيمية المؤثرة على الاداء التظيمي. وأن قيمة (F) المحسوبة (0.096) والمقارنة مع القيمة الجدولية بمستوى معنوية (0.05) والبالغة (4.084) وهذا يعني قبول الفرضية التي تتص على وجود علاقة تأثير ذو دلالة بين الموارد التظظيمية

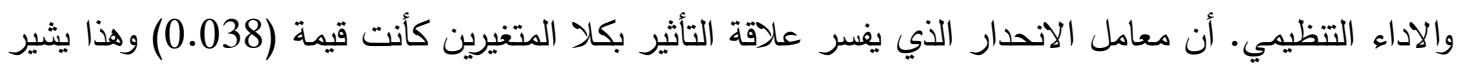
الى منحنى الانحدار غير جيد في تفسير العلاقة في ما بينهما فضلا عن عدم معنوية معامل الانحدار • بلغت

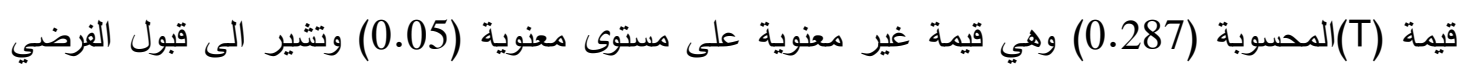
التي تتص هنالك تأثير بين المقدرات الجوهرية والاداء التتظيمي وفي ضوء ما تقدم وعلى وفق النتائج الإحصائية أعلاه يتضح أن هناك تأثير للمتغير المستقل

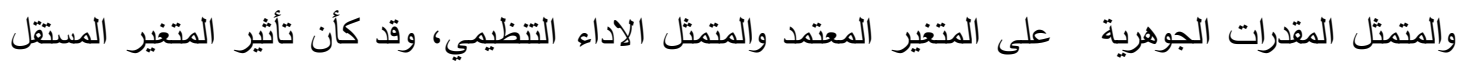
وفق معامل التحديد تأثيرا قوي، وبالتالي وفق هذه المعطيات يتطلب من هذه الشركة أن تولي اهتماما متزايدا في الرقابة على مقدراتها الجوهرية حتى تكون لديها القدرة الكافية في زيادة مستوى الاداء التظظيمي الى افضل فئل نتائج مككنه وبتالي تحص على مركز تتافسي جيد في سوق الاعمال. 


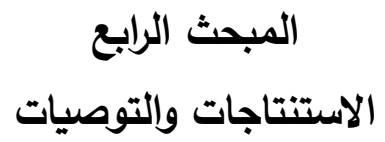

اولا -الاستنتاجات

1 - يعتبر العمل الجماعي من أهم وأقوى أبعاد المقدرات الجوهرية من حيث التأثثر الايجابي في مستوى الاداء التظظيمي في المنظمة المبحوثة، فكلما زاد مستوى العمل الجماعي في المنظمة كلما أنعكس وبشكل

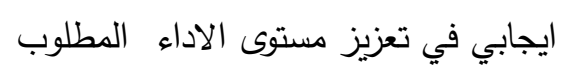

2 - أظهر التحليل هنالك علاقة ارتباط معنوية بين المقدرات الجوهرية بشكل عام والاداء التتظيمي في

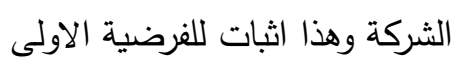

3 - أتضحت قوة المتغيرات المختارة في البحث (الموارد التظيمية ,مشاركة الرؤيا ,التمكين والتعاون) الامر

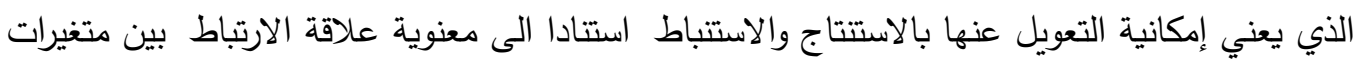

$$
\text { ابعاد الدراسة اي صحة الفرضيات (1,2,3) }
$$

4

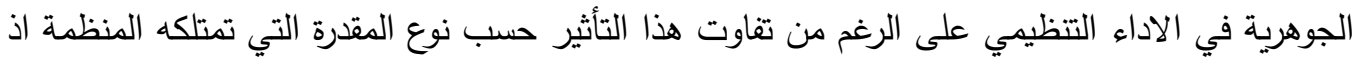

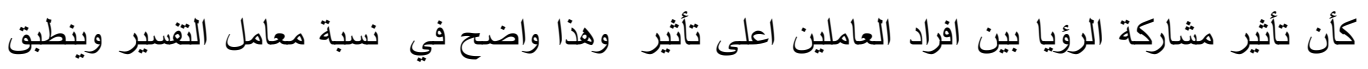

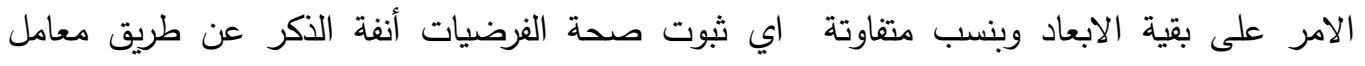

الانحدار و (t)

$$
\text { ثانيا - التوصيات }
$$

1-ضرورة التركيز على إعطاء فرص عمل وأولوية للعاملين وعلى وجه الأخص في المناصب الإدارية الذين

$$
\text { يمتلكون مهارات وصفات يتميزون بها عن غيرهم (مقدرات جوهري) ، وليس على أي اعتبارات أخرى. }
$$

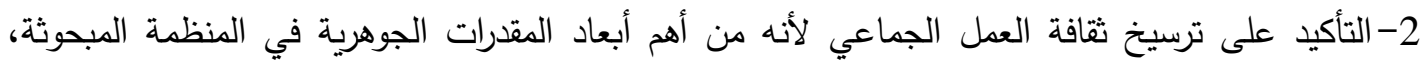

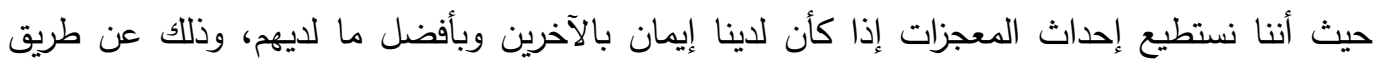
تشكيل فرق عمل ووضع نظام لذلك ومكافأة الإنجازات الجماعية.

3- العمل على تطوير وبناء المقدرات الجوهرية جديدة لرفع مستوى أداء المنظمة المبحوثة عن طريق تحديد

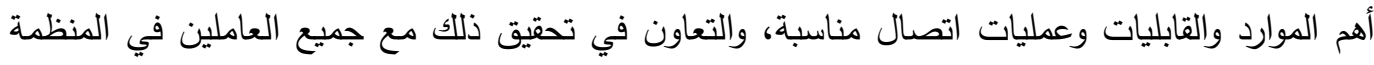

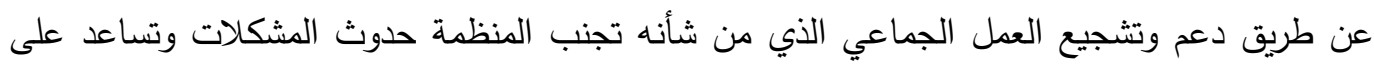
اتخاذ قرارات مناسبة بشأن تطوير المنظمة وإحداث تغييرات فيها تساعد على تحقيق نجاحات كبيرة

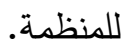

4-ضرورة اعتماد هيكل تنظيمي مرن يراعى فيه النظر إلى البيئة الخارجية للمنظمة المبحوثة لكي يتسنى لها مقارنة ما تمتلكه من قُدرات جوهرية مع منافسيها للتعرف على موقعها في السوق وأجراء التغييرات اللازمة في الوقت المناسب للحفاظ على استمرار عمل المنظمة ولضمان العلاقة بين التغيير التظظيمي والمقدرات

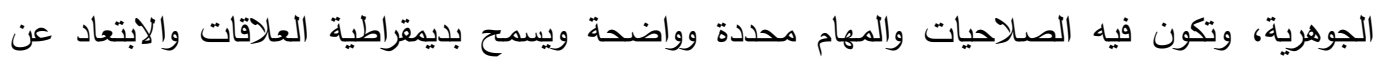
الإجراءات الروتينية، ويشجع الاتصالات والمشاركة الواسعة. 


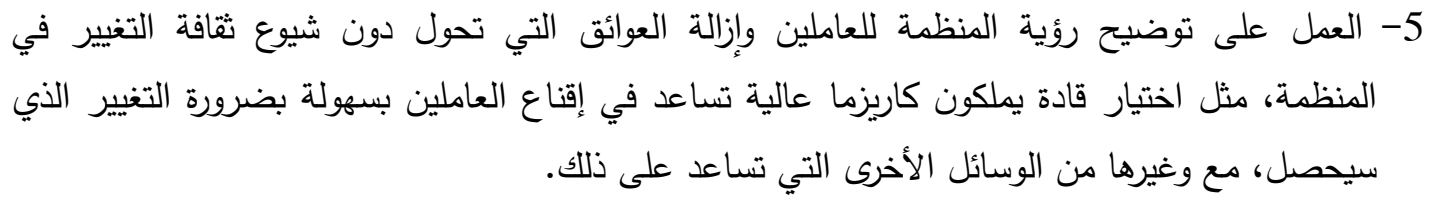

CONFLICT OF INTERESTS.

There are non-conflicts of interest.

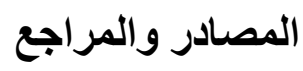

1-Merriam - Webster, "Collegiate Dictionary" 11th Edition, An Encyclopedia BRITANNICA Company, Springfield , Massachusetts,USA,2005

2- Christopher, Shea, M. and G. David Garson" Handbook of Public Information Systems" 3rd addition ,CRC Press, Taylor and Francis Group L.L.C, New York, USA,2010

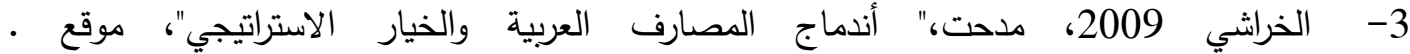

$$
\begin{aligned}
& \text { http://www.Ishraqa.com } \\
& \text { 4- - - الزوبعي2011, محمد فائز حسن, رسالة ماجستير بعنوان دور الاستراتيجيات المصرفية في تعزيز } \\
& \text { المقدرات الجوهرية للمصارف العراقية " دراسة في عينة من المصارف العراقية الحكومية و الخاصة. }
\end{aligned}
$$

5 - Zhang, Y. "Development of A Structured Framework For Core Competence Evaluation In The Manufacturing \& Service Industries", Ph.D. Dissertation, School of Engineering Sheffield Hallam University ,United Kindom,1999.

6 - White, C. "Strategic Management " , 1st edition, Palgrave Macmillan, New York, 2004

7 - Morden, T. "Principles of Strategic Management" 3rd edition, ASHGATE

Publishing Limited, England, 2007.

89- Pitelis, Christos N. "The Theory of the Growth of the Firm", 4th ed, Oxford University Press Inc. ,2009.

8- الحميري2014, بشار عباس, اكرم الياسري ,عواد الخالدي بحث بعنوان "انعكاسا المقدرات الجوهرية

على الاداء المصرفي في ضوء بطاقة العلامة المتوازنة دراسة تطبيقية لعينة من المصارف العراقية ,

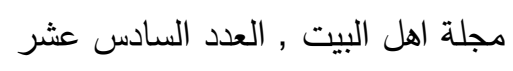

9 - القريوتي2010 ، محد قاسم " نظرية المنظمة والتنظيم " الطبعة الاولى، دار وائل، عمان.

10- Baker, W.E. and Sinkula, J.M. (1999), "The synergistic effect of market orientation and learning orientation on organizational performance', Academy of Marketing Science Journal, Vol. 27 No. 4, pp. 411-27,2000.

11- Ussahawanitchakit P., (2008), "Impacts of organizational learning on innovation orientation and firm efficiency: an empirical assessment of accounting firms in Thailand", International Journal of Business Research, Volume 8, Number 4.

12- www.healthyworkclimate.com

13- Croteau Ann-M, Solomon S., Raymond L., Bergeron F., (2001), "Organizational and Technological Infrastructures Alignment”, hicss, vol. 8, pp.8049, 34th Annual Hawaii International Conference on System Sciences (HICSS-34)-Volume 8, 2001 
14- Berger L. A. and Berger D. R., (2004), "The Talent Management Handbook", McGraw-Hill.

15 - Pearce, C. L., Sims, H. P., Cox, J. F., Ball, G., Schnell, E., Smith, K. A., \& Trevino, L. (2003). "Transactors, transformers and beyond: A multi-method development of a theoretical typology of leadership". Journal of Management Development, 22(4): 273-307.

16- Wheelen ,Hunger ,strategic management Addison-Wesley Pub (Sd); 4th edition (January 1993)

17- Richard, P.J., Devinney, T.M., Yip, G.S. \& Johnson, G. (2009), 'Measuring organizational performance: Towards methodological best practice', Journal of Management, vol. 35, no. 3, pp. 718-804.

18- Morgan, R.E. and Strong, C.A., (2003), "Business performance and dimensions of strategic orientation”, Journal of Business Research, Vol.56, No. 3: 163-176.

19- محمد عبدالله الظهران ادارة المعرفة مدخل نظري جامعة الملك فهد للبترول والمعادن 1989.

20- نجم عبود2008 "ادارة المعرفة: المفاهيم والاستراتيجيات والعمليات" الطبعة الثانية، مؤسسة الوراق للنشر

والتوزيع، عمان، الأردن.

21- Prahalad, C.K. \& Hamel, G. "The Core Competence of The Corporation" Harvard Business Review , Vol. 68, No. 3 ,1990. 